\title{
I. Humanidades y epistemología. Del efecto "Ya lo dijo MI COMPAÑERA” A LA METÁFORA DEL PEZ EN EL AGUA
}

La cultura, como el amor, no posee la capacidad de exigir. No ofrece garantías. $Y$, sin embargo, la única oportunidad para conquistar y proteger nuestra dignidad humana nos la ofrece la cultura, la educación liberal.

\section{Ítalo Calvino, Las ciudades invisibles.}

\begin{abstract}
"Buenos días. Mi nombre es Juan Sebastián López, hago parte del Departamento de Humanidades y les doy la bienvenida a la cátedra de Epistemología”. Ese es mi saludo inicial al principio de cada semestre. Después de hacer una breve pausa, en la que espero a que mis estudiantes me devuelvan el saludo, sigo con la introducción al curso: "supongo que tendrán alguna idea general de lo que estudiaremos a lo largo del semestre". Inmediatamente después, les espeto la siguiente pregunta: “¿qué entienden ustedes por epistemología?” Lo que viene a continuación es el momento más divertido de la cátedra en todo el semestre, al menos para mí. He oído respuestas de todo tipo; todas ellas me recuerdan la infinita variedad de formas en que los seres humanos nos enfrentamos al misterio. Algunos, en un tono áspero y con el ceño fruncido, sueltan un austero "No lo sé". Otros, haciendo alarde de carisma, proponen una definición tan errada en su contenido como encantadora en su formulación. Los peores, los que arruinan la fiesta, son aquellos que afirman, palabras más palabras menos, que la epistemología
\end{abstract}


se ocupa del problema del conocimiento. En ese momento reconozco que les está empezando a sonar la flauta. Entonces, todo se viene abajo: de ahí en adelante la estrategia de los estudiantes será la de hacer eco de esa respuesta que en su momento califiqué como más acertada. Solomon Asch (1951) llamaría a ese fenómeno "conformidad grupal”, pero bien podríamos entenderlo como el efecto "Ya lo dijo mi compañera".

En cualquier caso, la cátedra sigue su curso y termina con un saldo razonable de estudiantes aprobados que, seguramente, inscribirán otra materia del ciclo de humanidades el semestre próximo. Llegados a ese punto, ya no son ellos, mis estudiantes, sino yo, el profesor de humanidades, quien se enfrenta al misterio. Cuando veo a mis estudiantes salir del salón tras la última clase del semestre siempre me pregunto si habrán aprendido algo que luego les resulte importante y significativo para sus vidas, y si habré logrado inspirarles o al menos contribuir en algo a su proceso formativo. Las respuestas a tales preguntas tardan en llegar y han sido más bien escasas. Enseñar, sobre todo en la universidad, es un acto de fe; es como cultivar un campo de olivos, en el sentido de que éstos darán sus frutos tras un largo ciclo de crecimiento y maduración. El semestre pasa volando y yo nunca sabré si la cátedra de epistemología les habrá servido para algo.

Sin embargo, en la universidad-empresa del siglo XXI es cada vez más frecuente y común escuchar que la educación no posee tales dimensiones mistéricas y que, por el contrario, su objetivo consiste en instruir a un grupo de personas para que sean capaces de atender a las necesidades económicas de la sociedad actual. No comparto para nada esa forma de entender la educación, que me parece mezquina. Los seres humanos somos más que un engranaje en el sistema productivo; somos sobre todo ciudadanos, personas capaces de disfrutar, de aprender y enseñar, de imaginar futuros posibles y de solidarizarnos con las causas que consideramos justas. En este sentido, valdría la pena recordar que, como lo afirmó Kant (2012), uno de los principios del buen gobierno y, por extensión, de la educación, es tratar al hombre conforme a su dignidad, pues es "más que una máquina”.

La visión instrumental y transaccional de la vida en sociedad, del hombre y de la educación está cada vez más naturalizada y menos cuestionada. Vivimos y pensamos en una lógica de negocio (en tanto que ocupación lucrativa) más que de ocio (en tanto que ocupación lúdica, reposada, e ingeniosa), lo cual era impensable para los antiguos griegos, quienes creían que los hombres libres debían dedicarse al cultivo de sí mismos. Sin embargo, no se trata de ponernos melodramáticos ni de idealizar un pasado pisado. Se trata, más bien, de reconocer la importancia de examinar nuestra propia vida y de plantearnos objetivos más amplios, entendiendo que nuestro paso por este mundo es breve, y que pensar exclusivamente en términos de costo/beneficio sería un gran desperdicio. 
No podemos ser como el pez que describen McLuhan y Fiore (1985), incapaz de percibir el agua que constituye su medio natural e inmediato a falta de un anti-ambiente que se lo permita. En este orden de ideas, las humanidades deben ser para los estudiantes de cualquier programa un anti-ambiente tan desconcertante como necesario. De hecho, el anhelo profundo de todo profesor de humanidades es ser capaz de sacar al estudiante de su medio natural para que consiga, como lo hacía Leono con la espada del Augurio, ver más allá de lo evidente.

Ahora que hemos dado algunas puntadas sobre el sentido del título que encabeza este primer ensayo, cuya función es básicamente introductoria, conviene dedicar unas cuantas líneas a describir lo que sigue. Primero, echaremos mano de dos definiciones de las humanidades propias del ámbito universitario para llegar a proponer un concepto general. Luego, traeremos a colación algunos textos, ideas y autores que ayudan a comprender mejor el debate actual en torno a las humanidades. Esto nos permitirá, en un segundo momento, encarar de forma más decidida una cuestión más específica: lo que puede aportar la epistemología, entendida como parte del ciclo de formación humanística, a un estudiante universitario.

\section{Humanidades y educación superior: definiciones y debates}

\subsection{La tradición anglosajona y la tradición cristiano-tomista}

Algo que se aprende de la lectura de Aristóteles y Santo Tomás, y que ha hecho mella en la comunicación científica actual, es que tras toda definición hay polémicas, debates e intercambio de ideas. Por esta razón, me permitiré traer a colación algunas referencias que nos ayuden a comprender cuál podría ser el sentido y el valor actual de las humanidades.

Partiré de algunas definiciones de bolsillo, más amigables, para luego ahondar en ciertas polémicas en torno a las humanidades, el humanismo y la educación. La primera de ellas se encuentra en la página web del Stanford Humanities Center. Allí se propone, de forma clara y sencilla, una definición bastante vinculada a la tradición anglosajona y las artes liberales. Según ellos, las humanidades estarían directamente vinculadas al estudio de una experiencia humana que se ha manifestado en formas diversas a lo largo de la historia. El arte, la música, la filosofía y la literatura, en cuanto formas de expresión individual y manifestaciones culturales, nos permitirían establecer un vínculo con el pasado, dar sentido al presente y ensanchar nuestras perspectivas de futuro. De ahí que se las defina en términos del "estudio de cómo la gente procesa y documenta 
la experiencia humana", lo que brinda "un sentido de conexión con aquellos que han estado antes que nosotros, como también con nuestros contemporáneos” (Stanford Humanities Center, 2014).

Una segunda definición de las humanidades, bastante interesante también, es la que propone la Universidad Santo Tomás (USTA) a partir de lo que entiende por humanismo cristiano. En principio, el término humanismo se podría entender como un ideal de formación integral basado en la antigüedad clásica y en el estudio de las artes liberales, o sea, aquellas cultivadas por hombres libres (Rodríguez, 2001 p. 20). El Humanismo cristiano vendría a ser, sin embargo, una forma particular de humanismo, pues a la vez que se empeña en defender al hombre como valor absoluto afirma que es en la semejanza de éste con Dios donde reside el origen de la dignidad humana.

Para Tomás de Aquino, todas las personas están llamadas a la perfección y a la autonomía; sin embargo, Dios es el origen y el final del mundo humano. Así pues, no habría oposición, sino una sinergia perfecta, entre materia y espíritu, tal y como sucede entre Dios y el hombre. En otras palabras, una vida a plenitud no tendría por qué reñir con la vocación de todo hombre a dejar un legado espiritual (USTA, 2004).

A partir del discurso humanista-cristiano-tomista de la USTA, podríamos afirmar que las humanidades son un conjunto de disciplinas asentadas en la correlación Dios-hombre-mundo, cuya finalidad es la promoción del estudiante y su formación integral. Promoción equivale aquí a elevación gradual del estudiante, es decir, al pleno desarrollo de su capacidad estimativa autónoma ética, estética y epistemológica (Ídem). Las humanidades serían, además, un espacio de reflexión para que el estudiante se abra a la totalidad de lo real, para que reconozca la necesidad de establecer un diálogo de saberes, y para que logre una articulación significativa de ciencia y conciencia (USTA, 2004).

\subsection{El debate sobre las humanidades. Reliquias, guerreros y hombres de negocios}

Podríamos decir que, históricamente, las humanidades han sido objeto de polémicas que han terminado trastornando lo que pensamos de ellas. Hay quienes las instrumentalizan para defender un statu quo, y hay quienes las hacen a un lado por asociarlas a tradiciones decadentes.

Por un lado, para algunos grupos específicos de la sociedad, las humanidades poseen un aura aristocrática. Se alude a ellas en un tono reverencial, con términos nobles y elogiosos, como quien habla del Mercedes Benz W11 del abuelo. Así, la formación humanística se sigue asociando, para algunos, a una buena educación, muy old school y de alta cultura.

El problema radica en que, muy posiblemente, en estos sectores pase con las humanidades lo que pasó con la biblioteca que protagoniza aquel cuento maravilloso de Alfredo Iriarte (2013), "El apestoso martirio de una biblioteca". Allí se narra cómo el difunto Ulpiano Cleves Nariño 
deja en herencia a sus sobrinas, las hermanitas Cleves, una magnífica biblioteca que, al tiempo que se luce como símbolo de sapiencia y abolengo, se utiliza como reemplazo del papel higiénico que las susodichas herederas no pueden permitirse comprar por estar en un estado de quiebra vergonzante. La pregunta que nos plantea Iriarte es, pues, qué tan auténtica es la veneración que suscitan las humanidades en ciertos sectores de la sociedad, o si dicha veneración no es, más bien, una fachada para el elitismo.

La asociación entre humanidades y elitismo ha llevado a que se cuestione el valor, la actualidad y el sentido de una formación humanística. Así pues, si para algunos constituye un magnífico símbolo de estatus, por otra parte, y por esas mismas razones, para otros resulta obsoleta, inútil y excluyente. Este es el caso de las sociedades articuladas en torno al arquetipo del guerrero y/o del comerciante.

Si miramos al pasado encontraremos que, durante muchos siglos, el guerrero fue una figura arquetípica de hombría y, por consiguiente, de humanidad (léase la Historia de Heródoto, el Antiguo Testamento, La Ilíada, etc., o en el peor de los casos, véase 300). Los valores y relatos belicistas permitieron, durante siglos, que las sociedades se mantuvieran unidas y funcionaran de forma más o menos armónica. No extrańa, por tanto, que el ideal de hombre al estilo socrático, cínico o estoico fuera mirado con desconfianza y desdén.

Si hay una obra que por su ingenio y valor historiográfico permite hacernos una idea de la alergia que Sócrates producía entre sus contemporáneos, esa es Las Nubes, de Aristófanes ${ }^{1}$ (2007). Allí, un muchacho llamado Fidípides asiste, por orden de su padre, a una escuela llamada El Pensadero a aprender de Sócrates el arte de la argumentación y la oratoria. El caso es que Fidípides no parece muy seguro de permanecer en la escuela, por lo que Sócrates le presenta a dos personajes: el Argumento justo y el Argumento injusto. Ambos intentarán convencer a Fidípides de qué tipo de educación es mejor: si la educación tradicional, defendida por el Argumento justo, o la educación moderna, representada por Sócrates y defendida por el Argumento injusto.

Lo llamativo del debate es el significado que se esconde detrás de algunas descripciones. Estas son, precisamente, las que nos permiten comprender cuál era el ideal formativo de los sectores más conservadores de la Atenas clásica. A través del discurso del Argumento Justo, Aristófanes nos invita a reconocer la importancia que buena parte de los ciudadanos atenienses le asignaban a la obediencia, al respeto por la tradición, al honor, a la disciplina y al cultivo

1 Gran comediógrafo ateniense (444 a. C. - 385 a. C.). 
de la fuerza física. Así mismo, podemos advertir la incomodidad -o tal vez el miedo- que les producía la habilidad para argumentar y debatir, la rebeldía, la risa, el ingenio y la minuciosidad. La intervención del Argumento Justo resume muy bien esta situación:

\begin{abstract}
ARGUMENTO JUSTO: Hablaré, entonces, de cómo era la educación antiguamente, cuando yo iba viento en popa proclamando la justicia y la cordura estaba bien vista. Ante todo, era necesario que no se oyera la voz de un solo niño hablando; tenían que ir andando por las calles, en ordenadas filas, hacia la casa del maestro de música, juntos todos los de la misma aldea y desnudos, aunque la nieve cayera tan tupida como harina. Lo primero que aquél les enseñaba era una canción - La terrible Palas destructora de ciudades - que cantaban [...] entonando la armonía que habían recibido en herencia de sus padres. Y si uno de ellos se ponía a hacer bromas recibía una buena tunda de golpes como culpable de atentar contra las Musas [...]. En los banquetes no les estaba permitido [...] hacer melindres con la comida ni reír a carcajadas ni cruzar las piernas [...] ésas son las enseñanzas con las que mi método de educación produjo los héroes de Maratón [...]. Conque, muchacho, elígeme a mí, el Argumento Superior con entera confianza y aprenderás a odiar el ágora y a alejarte de los baños públicos; a sentir vergüenza ante lo que es vergonzoso y a encenderte si alguien te toma el pelo; a levantarte de tu asiento si se acercan personas de edad; a no portarte mal con tus padres y a no realizar, en suma, ningún acto vergonzoso que pueda manchar tu imagen de persona respetable. [...] pasarás el tiempo en el gimnasio, reluciente y fresco como una flor, y no discutiendo en el ágora idioteces sin sentido, como hacen ahora, dejándose arrastrar por asuntos de minucia [...]. Si haces lo que te digo y dedicas a ello tu atención tendrás siempre el pecho fuerte, la piel brillante, los hombros anchos, la lengua corta, el culo grande y la polla pequeña. Pero si te comportas como los de ahora, tendrás la piel pálida, los hombros estrechos, el pecho débil, la lengua larga, el culo breve y el nabo grande (Aristófanes, 2007, pp. 961-1013)
\end{abstract}

Como sugeríamos antes, los rasgos físicos que describe Aristófanes en boca del Argumento justo vendrían a caricaturizar los resultados de una y otra opción formativa. Por un lado está el hombre modélico: fornido, ágil y saludable (pecho firme, hombros anchos, culo grande y piel brillante); manso, respetuoso de la autoridad (lengua corta); y moderado en sus apetitos sexuales (polla pequeña). La otra opción es el mamarracho ${ }^{2}$ : un cuasi-hombre, debilucho y enfermizo (piel

2 O bardaje; o daoporculo (según la traducción de Gredos, que es la que utilizo aquí). 
pálida, hombros estrechos, pecho débil, culo breve); charlatán, embaucador y ocioso (lengua larga); e incapaz de controlar sus deseos (nabo grande). El hombre de perfil socrático, es decir, de carácter reflexivo y talante liberal, vendría a ser, según tales descripciones, un degenerado.

Algunos podrían pensar que, tras veinticinco siglos de carrera civilizatoria, la sociedad ha llegado a apreciar mucho más el ideal socrático de hombre reflexivo y crítico. Yo me atrevería a pensar lo contrario y a afirmar que las personas reflexivas, de lengua larga, curiosas, rebeldes y críticas, siempre serán una piedra en el zapato para sus dirigentes y amigos. Tendríamos que reconocer que muy en el fondo de nuestra condición humana hay algo que nos lleva a despreciar a las personas inquietas, lúcidas, inconformes y sońadoras. Preferimos la comodidad y la rutina mucho antes que la grandeza y la genialidad. Caemos así, como lo describe Victor Hugo (2010), en un error deplorable: cuando dejamos de preguntar y de pensar en cosas aparentemente inútiles para ahorrarnos dinero, problemas y esfuerzo, en realidad lo que hacemos es escatimar en conocimiento, cultura y grandeza.

Lo que sí ha venido cambiando con el paso de los siglos es el modelo de hombre deseable. El mundo antiguo ha dado lugar a otro tipo de orden social en el que el ideal de hombre que encarnaban Hércules o Leónidas ha ido perdiendo atractivo. El mundo moderno ha creado un arquetipo $\operatorname{trans}^{3} \mathrm{o}$ anti $\mathrm{i}^{4}$ humano, alternativo al del guerrero: el del hombre y la mujer ${ }^{5}$ de negocios. Este nuevo modelo aparece, si revisamos bien, en todos los grandes relatos contemporáneos. El lobo de Wall Street, En busca de la felicidad o El patrón del mal (para aquellos de gusto más criollo) vendrían a ser algunos ejemplos cercanos. ¿Por qué me refiero a este nuevo modelo como trans o anti humano? Precisamente por el credo de los negocios que formuló Otto Berman y que Mario Puzo (1970) hizo famoso en El Padrino: "it's just business, nothing personal”.

Desde un punto de vista estrictamente comercial, la dignidad humana no puede ser más un valor absoluto; ni siquiera el código de honor del que alardeaban los militares antiguos es ahora tan importante. La libertad, otrora principio innegociable, dentro de poco será entendida solo como libertad de mercado. Esta situación la retrata perfectamente Baudelaire al afirmar:

3 Según la RAE (2001): (pref.) Significa 'al otro lado'.

4 Según la RAE (2001): (pref.) Significa 'opuesto' o 'con propiedades contrarias'.

5 La presencia femenina es una evidencia positiva. Lo que representa en términos cualitativos hace parte de otra discusión. 
Cuando esto ocurra, el hijo huirá de su familia, pero no a los dieciocho años, sino a los doce, emancipado por su precocidad glotona: la abandonará no en busca de aventuras heroicas, no para liberar a una belleza prisionera en lo alto de una torre, no para inmortalizar una buhardilla con pensamientos sublimes, sino para fundar un comercio, para enriquecerse, y para hacerle la competencia a su infame papá (Baudelaire, 2000, p. 35).

El hombre de negocios, arquetipo desprovisto de humanidad, impacta en el núcleo del ideario educativo contemporáneo, con lo cual la educación se hace también trans o anti humana. Los fines de la educación actual están definidos por criterios como la empleabilidad, la flexibilidad laboral y la adecuación a las necesidades del sector productivo, poco más.

En la universidad-empresa las humanidades son vistas como el remanente de un pasado que ha dejado de ser significativo. Por consiguiente, aquellas personas que se dedican a la literatura, la filosofía, la historia y el estudio de las artes, etc., son definidas frecuentemente como ratones de biblioteca sin sentido práctico. No niego que la fama de los profesores de humanidades sea del todo injustificada. Sin embargo, el hecho de que funcionarios, educadores y estudiantes universitarios se refieran a las humanidades como "relleno" o "costura" da mucho en qué pensar. Pareciera que el fantasma del Argumento Justo aristofánico ha dejado sembrado en nuestro imaginario colectivo la negativa a pensar en idioteces sin sentido o a dejarnos arrastrar por asuntos de minucia. A la entrada de la universidad-empresa debería estar escrita en piedra la máxima del sentido común contemporáneo: "Lo que no sirve, que no estorbe".

Sin embargo, antes de dejarnos seducir por ese flautista de Hamelín que es el (sin) sentido común, o por los cantos de sirena de la opinión mayoritaria, conviene revisar los argumentos de quienes nadan contra la corriente y defienden el valor y la actualidad de las humanidades.

\subsubsection{Martha Nussbaum y los fines de la educación}

En El cultivo de la Humanidad (2001) y más tarde en Sin fines de lucro (2010), Martha Nussbaum vuelve sobre el pensamiento griego y romano para analizar el papel de las humanidades en el mundo actual. Según Nussbaum (2001), la educación se enfrenta, sobre todo, al reto de formar ciudadanos capaces de vivir en sociedades culturalmente diversas e internacionalizadas. La academia, entonces, tendría que ser un espacio en el que el mundo sea visto como un lugar de convivencia, en el que las personas aprendan a actuar como ciudadanos del mundo. En este orden de ideas, las humanidades tendrían un papel central al permitir al estudiante desarrollar tres capacidades: el autoexamen, el cosmopolitismo y la empatía. 
Para Nussbaum (2001), el ideal de una vida examinada hunde sus raíces en las tesis de los estoicos griegos y romanos sobre una educación liberal, aquella que libera la mente de la esclavitud de la rutina y forma personas que puedan actuar con sensibilidad y agudeza mental. Según la autora, vivir una vida examinada es un recurso esencial no solo para el autogobierno, sino también para la vida en sociedades democráticas. No podemos olvidar que la democracia necesita de ciudadanos que piensen por sí mismos, independientemente de la opinión de sus dirigentes. La reflexión y el autoexamen, entonces, nos permitirían afinar nuestro sentido de la sospecha ante cualquier creencia cuya legitimidad resida exclusivamente en la tradición o en la autoridad de quienes la promueven. Asimismo, nos ayudarían a comprender y valorar aquellos argumentos coherentes, razonables y justificados, vengan de donde vengan. La centralidad que las humanidades otorgan a la pregunta, la lógica y la argumentación resultan fundamentales para desarrollar esta capacidad crítica.

El cosmopolita o ciudadano del mundo es aquel hombre o mujer que defiende el valor de la vida humana por sobre cualquier otro tipo de vínculo identitario (familiar, local, regional, nacional, ideológico, etc.). El cosmopolitismo defiende una visión del mundo y de uno mismo más amplia, universal y general de lo acostumbrado. Para Nussbaum, en un mundo globalizado es necesario reconocer que, más allá de las distancias geográficas, la nacionalidad, la religión o la ideología política, existe un vínculo universal entre todas las mujeres y hombres por el mismo hecho de ser humanos.

Llegar a considerar cada uno de los lugares del mundo como nuestra patria resultaría mucho más sencillo si desde edades tempranas se nos enseñara más historia universal y se promoviera en las escuelas el estudio de culturas diferentes a la nuestra. Sin embargo, nunca es tarde para empezar. Las humanidades son, de hecho, una magnífica oportunidad para abrir nuestra mente a otras culturas y aventurarnos más allá de las estrechas lealtades de grupo (religión, partido político, nacionalidad, etc.) que a menudo nos hacen tanto dańo.

Finalmente, Nussbaum se refiere a la imaginación narrativa como la capacidad de identificarse a nivel mental y afectivo con otra persona, de ponerse en su lugar y de ver la vida desde su perspectiva particular. Esto implica ser un lector inteligente de la historia de esa persona y comprender sus emociones, deseos, motivaciones y anhelos. Según la autora, para poder liberar el pensamiento y vivir en sociedades democráticas, es esencial aprender a ver el mundo desde múltiples perspectivas. Una vez más, las humanidades podrían resultar decisivas para perfeccionar nuestra disposición natural a la empatía. El estudio del arte, la música, la filosofía, la literatura, etc., amplía nuestros umbrales perceptivos y nos brinda herramientas para ser mejores intérpretes de las acciones y discursos de los otros. 


\subsubsection{Jeffrey Alexander. La importancia de mirar con otros ojos}

Si para Martha Nussbaum las humanidades son un eslabón innegociable en la formación de ciudadanos críticos y solidarios, para Jeffrey Alexander (2009) las humanidades enseñan a investigadores y profesionales de otras áreas a mirar sus objetos de estudio con otros ojos. Según Alexander, la importancia que las humanidades confieren a la interpretación de los fenómenos, y no solo a su observación, permite a investigadores y profesionales acceder a las dimensiones ocultas, invisibles e inmateriales de aquello que estudian. Las humanidades vendrían a recordarnos, entonces, que los objetos de estudio de cada disciplina guardan una relación estrecha con su contexto histórico y social originario, y que por esta razón integran esa gran red de significados que llamamos cultura.

Alexander insiste, además, en que la secularización progresiva de las sociedades occidentales no equivale a la merma del componente simbólico, espiritual y emocional que articula la vida social. Según él, seguimos creando mitos que nos permitan trascender la banalidad de la vida material, necesitamos contar historias tanto para sentir que progresamos como para procesar el dolor y la violencia, y constantemente diferenciamos entre lo sagrado y lo profano a fin de perseguir el bien y protegernos del mal (Alexander, 2003).

El sentido y el valor de estudiar humanidades, según Alexander, va muy en la línea de la famosa frase de Antoine de Saint-Exupéry: "Lo esencial es invisible a los ojos" (Saint-Exupéry, 2001, p. 40). Si reflexionamos sobre fuerzas sociales invisibles tales como la autoridad, la indignación o la solidaridad nos daremos cuenta de que, efectivamente, nos movemos en medio de redes de significados y poderes inmateriales que vale la pena reconocer e interpretar. Ahora bien, esto no solo aplica a dichas fuerzas invisibles. Pensemos por un momento en la tecnología, las obras de ingeniería y los bienes de consumo: ¿los vemos solo como cosas?, ¿podemos valorar su impacto solamente a partir de su función y utilidad inmediata?, ¿no están acaso rodeados de una fuerza simbólica, inmaterial, invisible que los hace especiales y significativos para nosotros? Pues bien, para Alexander (2003) son precisamente esas dimensiones simbólicas, inmateriales e invisibles las que es necesario aprender a identificar e interpretar. Estudiar humanidades, entonces, nos ayudaría a ensanchar nuestros umbrales perceptivos y ser mejores analistas simbólicos.

Para Alexander, de la mano de las humanidades podemos aprender a ver la sociedad como un gran relato y nuestras acciones y objetos de estudio como textos. Este no es para nada un aprendizaje menor. Basta echar una mirada a lo que sucede en las redes sociales, los foros en Internet, la televisión, los videojuegos o el cine para comprender que vivimos en una sociedad de relatos trans-mediáticos. Las declaraciones de un político terminan siendo convertidas en un meme 
compartido una y otra vez en Facebook; Mariana Pajón suelta el famoso trending topic "era gol de Yepes" en medio de una entrevista televisada; Obama se hace una selfie con David Cameron en el funeral de Mandela; la máscara de Guy Fawkes que utilizó el protagonista de $V$ de Venganza pasó a ser uno de los símbolos distintivos de la organización Anonymous; "La Última Cena" de Da Vinci ha sido emulada por multitud de pintores y fotógrafos y es la piedra angular del bestseller de Dan Brown; Apocalyptica produce un cover soberbio de la icónica Nothing Else Matters. La lista podría extenderse hasta el infinito y definitivamente pasaría por las tesis de grado, los libros de texto y las aulas de clase, donde se repiten una y otra vez las ideas de tal o cual intelectual de referencia. Todo esto nos lleva a concluir que, sin importar si estudiamos administración, ingeniería, negocios, sociología, comunicación o economía, es necesario aprender a ver relaciones entre fenómenos aparentemente desconectados; o, en otras palabras, a conectar los puntos (Jobs, 2005).

\subsubsection{Edgar Morin. La religación ética y los fines cualitativos de la educación}

La capacidad de articular, unir o enlazar que estimulan una educación humanista es el tema central del prólogo, escrito por Edgar Morin (2014), del Acuerdo por lo superior 20346. Según Morin, la educación superior debe promover una visión del hombre, del conocimiento y del mundo basada en dos principios. Primero, que todo proceso educativo tiene una finalidad cualitativa: la convivencia y el buen vivir. Segundo, que la educación debe permitir una religación ética del sistema, es decir, la articulación "mente-corazón, materia-espíritu, mediosfines, sujeto-objeto" (Morin, 2014, p. 7).

A juicio de Morin, la educación superior no puede perder de vista lo que en el fondo de veras cuenta: la dignidad y el desarrollo espiritual del hombre como sujeto libre y amable. Desde este punto de vista, nuestro sistema educativo será exitoso y pertinente solo si se ordena bajo criterios de equidad y justicia, y no por la demanda mercantil o el afán de lucro. En este sentido, para Morin (2014), el discurso humanista da armonía y sentido de la finalidad al acto educativo, por cuanto reconoce que el "individuo-persona-ciudadano" es el "verdadero punto de convergencia de los ejes cognitivos, psicológicos, físicos, sociales, políticos, religiosos y financieros” (p. 8).

6 Acuerdo por lo Superior 2034 es un documento de política pública para la educación superior presentado en junio de 2014 por el Consejo Nacional de Educación Superior. Allí se plantean "los grandes cursos de acción prioritaria que debe asumir Colombia en educación superior para las próximas dos décadas" (CESU, 2014). 
Cuando Morin habla de religar, o articular, se refiere al acto de entrelazar con el pensamiento el individuo, la sociedad y la naturaleza. Según él, en un mundo de hiperespecialistas se hace necesario tener esa inteligencia religante para con uno mismo y para con la sociedad. Su posición se torna especialmente lúcida si nos preguntamos seriamente por qué, ante la evidencia de que todo en el universo está conectado, seguimos empeñados en dividir, aislar y segmentar. Probablemente padecemos de lo que José Martí, cubano ilustre, llamaba el síndrome del isleño: creer que nuestra isla es el mundo entero.

¿Cómo curarnos de esa miopía del conocimiento que nos impide ver más allá de la nariz? Morin (2014) afirma que necesitamos apostarle, como país, a un conocimiento reflexivo, "capaz de criticar el propio conocimiento", apto para referirse no solo a nuestros objetos de estudio en específico, sino "al contexto, a lo global y a lo multidimensional".

\subsection{En conclusión, ¿por qué son importantes las humanidades?}

Podríamos debatir ampliamente sobre si las humanidades tienen alguna utilidad. Yo, personalmente, creo que sí la tienen, pero también considero que un criterio de utilidad no resulta suficiente para valorarlas de forma integral. Las humanidades son mucho más que un conjunto de saberes útiles; son disciplinas liberadoras, que rebasan los límites de lo instrumental y permiten al estudiante aspirar a una vida plena, y no solo a una vida cómoda. Las humanidades serían, entonces, una magnífica oportunidad para volver sobre aquellas cuestiones tan inútiles como importantes a la hora de dar sentido a nuestras vidas: ¿quiénes somos?, ¿de dónde venimos? y ¿̨hacia dónde vamos? Cabría recordar aquí la sentencia de Nietzsche, según la cual "el que encuentra un por qué para vivir es capaz de enfrentar cualquier cómo” (2004, p. 35).

Gadamer (1984) dejó muy claro que la tradición humanística se debe valorar bajo un criterio de significación y no de utilidad instrumental. En ese orden de ideas, las humanidades entrarían en ese conjunto de cosas cuyo valor no depende de los usos que se le den, sino de lo que significan en un sentido espiritual (intelectual, estético, emocional, moral, etc.). Théophille Gauthier describe así la diferencia entre valorar una cosa por su utilidad y valorarla por su significado:

Nada de lo que resulta hermoso es indispensable para la vida [...] Yo renunciaría, sin embargo, antes a las patatas que a las rosas, y creo que en el mundo solo un utilitario sería capaz de arrancar un parterre de tulipanes para plantar coles [...] Solo es realmente hermoso lo que no sirve para nada [...] El rincón más útil de una casa son las letrinas [...] Yo soy de aquellos para quienes 
lo superfluo es lo necesario. Prefiero las cosas y las personas en razón inversa a los servicios que me puedan prestar. Prefiero un jarrón chino, sembrado de dragones y mandarines, que no sirve para nada, a uno que me sea útil. Renunciaría gustoso a mi condición de ciudadano francés por contemplar un auténtico cuadro de Rafael [...] Vendería mi calzón por un anillo y mi pan por tener mermelada [...] Ved, pues, cómo los principios utilitarios están lejos de ser los míos. [...] ¿Para qué sirve esto? Sirve para ser bello. ¿No es suficiente? (Gauthier, 2007, pp. 27-29).

Siguiendo de nuevo a Gadamer (1984), podríamos decir que la tradición humanística nos recuerda que una visión materialista y utilitaria del mundo, de las relaciones sociales y del conocimiento nunca será suficiente para saciar el anhelo humano por dar sentido a la existencia. Frente a una educación instruccional, especializante y mercantil, desde el discurso humanístico se habla insistentemente de formación, es decir de una educación que involucre no solo la consecución de objetivos técnicos, sino toda la vida espiritual, la sensibilidad y el carácter del individuo. Así mismo, ante la "astucia práctica” y la "capacidad de adaptación” que pregona el individualismo contemporáneo, las humanidades reivindican la idea de sensus communis como orientación de la voluntad en función de una vida social virtuosa y amable. Vivir en clave de sensus communis implica, entonces, preocuparnos no solo por aquello que es posible, sino también por aquello que es correcto; es "comprender la humanidad en el sentido del buen vivir, de la solidaridad, de la empatía” (Ídem, p. 55).

A diario nos topamos con evidencias de los sinsentidos que conforman el mundo en que vivimos, sinsentidos que aparecen también en el escenario educativo. Es muy fácil comprobar que somos a la vez víctimas y reproductores de un consumismo irreflexivo basado en las exigencias cambiantes de la moda (Ídem, p. 69). En el plano de lo político, podríamos decir que nos merecemos los gobernantes que tenemos, pues somos nosotros, o en el peor de los casos nuestra pereza y cobardía cívica, quienes los elegimos y los mantenemos en el poder. Así pues, contra una ciudadanía irreflexiva, las humanidades nos recuerdan la importancia de cultivar nuestro sentido del gusto y nuestra capacidad de juicio. El gusto, por sí mismo, nos muestra que no somos seres que vivamos únicamente en función de la satisfacción de necesidades, sino que poseemos una capacidad de disfrute que merece ser aprovechada en aras de una vida más plena y feliz.

El gusto, afirma Gadamer (Ídem, p. 69), es una forma de conocimiento y un fenómeno social de primer rango; por ello no se puede comparar a la moda, porque el primero implica la mesura y la intervención del juicio. Esta mediación de la conciencia aplica también en la vida política y sobre todo en nuestros deberes ciudadanos. No podemos permitir que otros sigan 
tomando las decisiones realmente importantes por nosotros. La capacidad de juzgar sobre lo justo e injusto, y sobre lo que puede ser de provecho común, es hoy más necesaria que nunca. Esto nos lleva a analizar cuál podría ser el aporte de las humanidades a los debates sobre ciencia y tecnología en el mundo actual. Ese será el tema que abordaremos en la siguiente sección.

\section{La epistemología como vínculo entre ciencia y conciencia}

\subsection{La epistemología desde el punto de vista de las humanidades}

Cuando hablamos de "epistemología" no nos referimos a un concepto unívoco. Como afirma Padrón (2007), existen múltiples formas de entender la epistemología. A fin de ir aclarando el campo en el que queremos movernos, la primera pregunta que valdría la pena hacer sería: ¿qué estudia propiamente la epistemología? Pues bien, para unos la epistemología es un tratado filosófico que estudia el conocimiento en general, mientras que para otros es una disciplina que estudia la forma particular de conocimiento científico.

No basta, sin embargo, con entrever el panorama de aquello que estudia la epistemología, sino que también es necesario comprender el cómo, es decir, la perspectiva desde la cual se estudia el conocimiento en general o el conocimiento científico en particular. En este sentido, siguiendo todavía a Padrón, tendríamos que decir que existen tres posibilidades: la primera, hacer epistemología desde una perspectiva más analítica, al modo del proyecto del Círculo de Viena, bajo la pretensión de evaluar la validez y justificación de los enunciados que componen un tratado científico y de los protocolos que dan forma a las comunidades científicas. La segunda opción sería hacer de la epistemología una "ciencia fáctica obligada a explicar, mediante teorías contrastables, los procesos del conocimiento científico, del mismo modo que la biología se obliga a explicar los hechos orgánicos o en que la lingüística se obliga a explicar los hechos de lenguaje”. La tercera opción sería la de una epistemología como "reflexión libre, tanto en un plano filosófico no analítico como en un plano socio-histórico, cultural, psicológico y antropológico, sin demasiadas preocupaciones acerca de los linderos entre esas áreas" (Padrón, 2007, p. 4).

Tenemos, entonces, dos opciones sobre aquello que estudia la epistemología (el conocimiento a secas y el conocimiento científico) y tres posibilidades de abordaje (analítico, ciencia fáctica y reflexión libre interdisciplinar). Conviene, pues, reflexionar sobre qué versión de epistemología se adecua mejor al proyecto de las humanidades como ciclo de formación integral. 
Si reconocemos que la epistemología es una cátedra transversal a todas las carreras, como sucede en la Universidad Santo Tomás, a mi juicio tendríamos que privilegiar un abordaje interdisciplinar, dinámico y asequible en torno al fenómeno del conocimiento. Esto nos permitiría llevar a cabo una lectura atenta al contexto histórico y culturalmente enriquecida sobre esa forma tan particular de conocimiento que llamamos ciencia, así como del mundo de las profesiones y las disciplinas. Una epistemología entendida como parte del discurso humanístico tendría que promover una visión interrelacionada de la ciencia, la tecnología y la sociedad a través del análisis de problemáticas históricas, culturales y políticas, y mediante recursos mediáticos, artísticos y documentales muy variados.

La epistemología, así entendida, no tendría una función normativa ni sobre la ciencia ni sobre el mundo profesional, sino más bien un papel dialogante, crítico y reflexivo. En no pocas ocasiones la epistemología ha derivado en una especie de cartilla filosófica sobre cuáles son los límites, los protocolos y los objetivos que se deberían admitir como válidos en el quehacer científico. Creo que dichos intentos terminan siendo soberbios e ingenuos por la sencilla razón de que los humanistas, y en especial los filósofos, no han sido formados bajo una lógica científica que les permita criticar la ciencia desde dentro. La física teórica no busca su justificación en la filosofía, sino en la física misma. Lo mismo aplica para otros campos del saber. Los protocolos y enunciados que dan forma a una ciencia o disciplina se generan y validan en el interior de las mismas, por lo que un discurso filosófico orientado a tales fines se hace, como poco, innecesario.

Las humanidades pueden aportar, en cambio, en la construcción de una visión externalista sobre el fenómeno científico, es decir sobre sus fundamentos filosóficos, su sentido histórico, su importancia cultural y su finalidad social. Una epistemología concebida desde estos parámetros permitiría comprender que la ciencia y la educación superior no son fenómenos que se agotan en sí mismos ni en su función económica, sino que se deben a la sociedad y a la cultura que los abriga.

En términos de ciencia y formación profesional, los abordajes internalista y externalista son igualmente importantes. El físico, el antropólogo, el ingeniero y el administrador, etc., no solamente deben tener claro el discurso, los métodos y los problemas específicos de su disciplina. Se espera de ellos, además, capacidad de analizar críticamente aquello que estudian, claridad para reconocer su responsabilidad social, y agudeza para detectar los vínculos que unen su disciplina a otros campos del saber.

En un mundo tecnologizado, competitivo, globalizado y multicultural como en el que vivimos, más allá de los límites que impone la lógica de mercado se advierte una demanda creciente de reflexividad. Se espera, entonces, que los futuros profesionales sean capaces de una mirada crítica y responsable sobre su propia disciplina. Bastaría con hacer a un lado nuestros intereses de lucro por un momento para 
darnos cuenta de que los problemas que aquejan nuestras sociedades no pueden ser resueltos sino desde la articulación de sus dimensiones técnicas, políticas y morales (Wallerstein, 2001).

\subsection{Tres razones a favor de la epistemología}

Cuando Tomás de Aquino se ocupaba de una cuestión (Quaestio), usualmente lo hacía a través de artículos en los que, una vez planeado el problema a tratar, se consideraban algunos argumentos, generalmente tres. Siguiendo el ejemplo del Aquinate, me gustaría proponer tres razones por los cuales considero que (respondeo dicendum quod) vale la pena estudiar epistemología según el criterio humanista de articular ciencia y conciencia.

\subsubsection{Primera: en el mundo actual la información es un commodity, mientras que la capacidad de darle sentido es tan escasa como valiosa.}

Cuando hablamos de commodity nos referimos a una mercancía genérica, abundante, accesible y barata. Para autores como Carr $(2008 ; 2010)$, Cobo y Moravec (2011), la información cumple actualmente con tales características. Vivimos, de hecho, en una sociedad informacional, que ha hecho de los bits y de Internet su recurso esencial para autoorganizarse (Castells, 1997).

Sin embargo, información no equivale a conocimiento, de la misma forma que informar no es comunicar (Wolton, 2011). En la actualidad, es cierto, gozamos del privilegio de acceder de forma rápida, barata y casi que inmediata a información de todo tipo. También es verdad que dicha facilidad en el acceso a la información podría ser considerada como el principio de un proceso nunca antes visto de democratización del conocimiento, así como de una transformación en los modos de producirlo. No obstante, valdría la pena preguntarnos cómo estamos aprovechando esta situación privilegiada.

Anderson y Wolff (2010) escribieron un artículo emblemático sobre los usos que la gente está dando a ese recurso maravilloso que es Internet. En pocas palabras, los autores aseguran que los usos de Internet están cada vez más “domesticados”, y que la utopía de la red como una plataforma para la libertad, la autonomía, la participación y el trabajo colaborativo ha ido perdiendo fuerza. En su lugar, afirman Anderson y Wolff, lo que tenemos ahora es una navegación cada vez más atenida a fines comerciales, en la que el internauta se limita a comprar online, mantener sus perfiles en dos o tres redes sociales, consultar direcciones, teléfonos y novedades, y sobretodo ver videos. 
Pareciera, pues, que la abundancia de información no ha traído consigo abundancia de creatividad, ni de autonomía, ni de genialidad. Por el contrario, el escenario actual se podría resumir en el siguiente comentario de Sampedro (2006b, p. 34), que indica que el problema no es de desarrollo tecnológico ni de acceso a la información sino de "modos de mirar":

La primera mirada (sobre Internet) identifica un conjunto de nudos entrelazados, capaces de abarcarlo todo, adaptándose y extendiéndose hasta el infinito. Esa es la metáfora ilusionante de la "sociedad red" que las nuevas tecnologías ayudarían a tejer. Su antónimo es la Red como conjunto de vacíos apenas unidos por un hilo... y ahí estamos, con demasiados vacíos que llenar (Sampedro, 2006b, p. 34).

De ser cierta la afirmación de Sampedro, podríamos afirmar que vivimos una paradoja histórica: la nuestra es una época en la que abunda la información pero escasea la sensatez y el sentido. Según Burke (2012), la nuestra es una época de gigantes de la información, pero también de enanos del conocimiento. En ese caso, ¿no sería completamente necesario dar un salto de calidad y empezar a preocuparnos más decididamente por la cuestión del conocimiento en el mundo actual?

Vivimos rodeados de información cuantitativamente abundante pero cualitativamente dudosa. "Rincón del Vago" o "Monografías" son palabras que en nuestro imaginario denotan la facilidad de la que gozamos actualmente para encontrar atajos. El problema sucede cuando el atajo termina por convertirse en el camino principal. El acceso y la identificación de fuentes de información fiables y de calidad es una tarea cada vez más complicada para muchos estudiantes. ¿No sería necesario, entonces, armarnos de un aparato crítico y de un acervo cultural que nos permita separar el trigo de la cizańa? Más que información, que ya la tenemos, requerimos capacidad de juicio para valorar su calidad. En un mundo donde abundan las respuestas fáciles pareciera que lo que en verdad se necesita es empezar a hacerse preguntas difíciles.

Al ser una mercancía, la información que nos sale al paso casi siempre viene rodeada de un aura de novedad. De ahí, nos hacemos una idea falsa del mundo: imaginamos que nada de lo que está sucediendo hoy ha pasado antes ni volverá a acontecer después. Si se nos dificulta comprender el mundo en que vivimos es en buena parte porque no tenemos una formación en historia que nos permita establecer relaciones entre acontecimientos aparentemente desconectados. Por tanto, hoy más que nunca necesitamos formarnos bajo un criterio de generalidad y de atención a la historia del conocimiento. Solo así dejaremos de engrosar las filas de espectadores 
fascinados y pasaremos a compartir un sitio con todos aquellos que entienden que cualquier avance, descubrimiento o logro profesional o intelectual requiere andar a hombros de gigantes.

\subsubsection{Segunda: la ciencia se entiende actualmente como algo "sagrado", cuya veracidad no se cuestiona aunque no se acaben de entender sus enunciados}

El estatus de sacralidad del que goza la ciencia en el mundo actual no se lo han inventado los científicos. Cuando hablamos de algo "sagrado" nos referimos a que en el imaginario colectivo el científico habita un mundo ideal, extra-ordinario, casi inaccesible, ajeno a los afanes cotidianos y sin mucha relación con el mundo real, profano (Durkheim, 1993).

El oficio del científico, sobre todo en Colombia, se mira aún con extrañeza. Mientras en países como Alemania se suele llamar "doctor" únicamente a quienes tienen un doctorado y se dedican a la investigación, en Colombia llamamos "doctor" a todo aquel que tenga su propia oficina. De hecho, es usual que muchas personas pidan a sus empleados, subalternos o conocidos que les llamen de ese modo. Esta práctica cultural indica: primero, que asociamos estatus a conocimiento, así no tengamos conciencia plena de ello; segundo, que en Colombia ser un "doctor" de verdad es algo tan poco común que el concepto ha terminado desvinculado de su referente real.

Traemos a colación el caso de los "doctores" colombianos porque una forma de valorar el estado de la ciencia en cada país es atender a la cantidad, la calidad y el trabajo de sus doctores (los reales). Al respecto, Martínez afirma:

Mientras Brasil o Chile tienen un porcentaje de doctorados de 0,44 y 0,18 , respectivamente entre las personas de 25 y 29 años, la proporción en Colombia es apenas de 0,007 por ciento. Hoy el país tiene 13,22 doctores por cada 100.000 habitantes, cifras que parecen bajas si se comparan con 44,8 y 28,1 que tienen Brasil y Chile (Martínez, 2014, p. 22).

Los datos que proporciona Martínez indican que queda mucho por andar para que la sociedad colombiana comprenda el valor y el oficio de los doctores, de los que en gran medida depende de que la sociedad en general se familiarice con la cultura científica e investigativa. Insistimos: al no haber suficientes científicos, la ciencia sigue siendo para nosotros una cuestión lejana y rodeada de un aura de misterio.

En la otra cara de la misma moneda está la ideología cientificista, frente a la que la mayoría de las personas se muestran tan acríticas como fascinadas. Pese a que no acabamos de entender qué es la ciencia y cómo funciona, todo lo que suene a científico despierta en nosotros una 
fascinación especial: el cine de ciencia-ficción, uno de los géneros más taquilleros, nos asombra y aterroriza con las imágenes del futuro que nos espera; abundan los foros y las comunidades virtuales dedicados a discutir, escena por escena, cada una de las temporadas de The Big Bang Theory, Doctor House o Masters of Sex; Giorgio Tsoukalos, uno de los "expertos" en extraterrestres de la serie Alienígenas ancestrales, es toda una figura mediática.

Solo a la ideología cientificista -que contrasta con el ideal no-dogmático de la ciencia real- se le puede achacar la responsabilidad de que la frase "un estudio demuestra que" sea la mejor manera de zanjar una discusión o de dotar de autoridad una noticia. El falso argumento ad verecundiam", según el cual: "un estudio llevado a cabo por científicos del instituto o la universidad X demuestra que" acompańa, peligrosa e irresponsablemente, toda clase de relatos periodísticos y leyendas urbanas. Este recurso a "la evidencia" y "lo científico" -y no la ciencia, insistimos- se ha convertido en una forma de hacer veraz casi cualquier idea, por retorcida que esta sea, sin necesidad de mayores discusiones. Nos basta con saber que se hizo una encuesta o un experimento para bajar la cabeza y pasar a otro tema.

El problema de la "dictadura de los estudios" es el mismo que el de los falsos doctores. En ambos casos se evidencia que la sociedad no se encuentra familiarizada con la cultura científica. Esta carencia de recursos críticos para analizar un estudio o enunciado científico hace que adoptemos una actitud ingenua ante la ciencia y lo que se quiere maquillar como tal. Una vez más, resulta que no tenemos cómo distinguir el trigo de la cizańa.

Debemos prepararnos, entonces, para comprender mejor las lógicas que ordenan la cultura científica a fin de desenvolvernos en ella con suficiencia y someterlas a crítica. Si no tomamos en serio nuestra formación científica y epistemológica, no tendremos forma de valorar, generar, transferir y usar el conocimiento. Reflexionar en torno al conocimiento científico ensancha y al mismo tiempo agudiza nuestra mirada. Ser un estudiante universitario implica asumir la responsabilidad de ir más allá de la inmediatez de la técnica del saber hacer, para formarse un criterio. Se espera de un profesional, como aparece en el juramento hipocrático, que emplee no solamente todas sus fuerzas, su pericia técnica, sino también toda su inteligencia en cumplir la misión a la que ha sido llamado.

7 Abuso del recurso a la autoridad de un experto. 


\title{
2.2.3. Tercera: necesitamos un medio de contraste que nos haga más conscientes de nuestra profesión o disciplina
}

David Foster Wallace (2012) pronunció en 2005 un discurso maravilloso ante los graduandos del Kenyon College sobre el sentido de la formación humanística. El discurso empieza así:

\begin{abstract}
Había una vez dos peces jóvenes que iban nadando y se encontraron por casualidad con un pez mayor que nadaba en dirección contraria; el pez mayor los saludó con la cabeza y les dijo: "Buenos días, chicos. ¿Cómo está el agua?”. Los dos peces jóvenes siguieron nadando un trecho, por fin uno de ellos miró al otro y le dijo: “¿Qué demonios es el agua?”.
\end{abstract}

Líneas después, el autor advierte que su parábola no trata sobre la autoridad de los peces viejos. Argumenta, en cambio, que "el sentido inmediato de la historia de los peces no es más que el hecho de que las realidades más obvias, ubicuas e importantes son a menudo las que más cuesta ver y las más difíciles de explicar" (2012).

Según Wallace, graduarse implica, ante todo, un cambio de ambiente. El ejercicio de la carrera profesional que acompańa la vida adulta puede volverse rutinario y frustrante, hasta el punto de perder todo sentido. En ese escenario se debe enfrentar el dilema de vivir la vida y la opción profesional de forma irreflexiva y narcisista, o vivirla significativamente; estando atentos y conscientes; siendo imaginativos y compasivos. Wallace concluye que la decisión depende de cada uno: podemos optar por una educación liberal, que nos ayude a ser conscientes respecto de lo que tiene sentido y lo que no, o podemos decantarnos por el piloto automático, la inconciencia, la "carrera de ratas" (Ídem, 2012) y la constante sensación de haber perdido el rumbo.

Vista de esa forma generosa y vital, una epistemología concebida como parte del ciclo de formación humanística tiene poca relación con el conocimiento por sí mismo. Más bien, se fundamenta en la conciencia que debe acompañar todo conocimiento para que éste resulte significativo. En conclusión, la cátedra de epistemología es un escenario privilegiado para reflexionar con serenidad, sin atajos, sobre el mundo de la ciencia, la tecnología y las profesiones bajo la pretensión de que estas tres nos sean significativas, no solo útiles. 


\section{Referencias}

Alexander, J. C. (2003). The Meanings of Social Life. A Cultural Sociology. Edición Kindle. Recuperado de Amazon.com.

Alexander, J. C. (2009). What We Learn from the Humanities? Newsletter of Sociology of Culture, 23(1), 4-8.

Anderson, C. y Wolff, M. (2010): The Web is Dead. Long live the Internet. Wired, Septiembre. Recuperado de: http://www.wired.com/magazine/2010/08/ff_webrip/

Aristófanes (2007). Las nubes. En Comedias II. Madrid: Gredos.

Asch, S. (1951). Effects of group pressure on the modification and distortion of judgements. En Guetzkow, H. (Ed.). Group, leadership and men. Pittsburgh: Carnegie Press.

Baudelaire, C. (2000). Pensamientos y notas autobiográficas. En Poesía completa. Escritos autobiográficos. Los paraísos artificiales. Critica artística, literaria y musical. Madrid: Espasa.

Burke, P. (2012). Historia social del conocimiento. De la Enciclopedia a la Wikipedia. Barcelona: Paidós.

Calvino, I. (1985). Las ciudades invisibles. (A. Bernárdez, trad.), Barcelona: Minotauro.

Carr, N. (2008). Is Google Making Us Stupid? What the Internet is doing to our brains. The Atlantic, 01-06.

Carr, N. (2010). Superficiales. ¿Qué está haciendo Internet con nuestras mentes? Madrid: Taurus.

Castells, M. (1997). La Era de la Información. Vol. 1. La sociedad red. Madrid: Alianza.

Cobo, C. y Moravec, J. (2011). Aprendizaje invisible. Hacia una nueva ecología de la educación. Barcelona: Publicacions i Edicions de la Universitat de Barcelona.

De Saint-Exupéry, A. (2001). El principito. Santiago de Chile: Pehuén Editores.

Durkheim, E. (1992). Las formas elementales de la vida religiosa. Madrid: Alianza.

Gadamer, H. G. (1984). Verdad y Método. Salamanca: Sígueme.

Gauthier, T. (2007). Prefacio del autor. En Madmoiselle de Maupin. Barcelona: Mondadori.

Hugo, V. (2010). Du péril de l'ignorance. París: Les éditions du Sonneur.

Iriarte, A. (2013). El hidalgo de Bragueta y otras fábulas de Iriarte. Bogotá: Planeta.

Jobs, S. (2005). Commencement speech at Stanford University. [archivo de video], Recuperado de: https:// www.youtube.com/watch?v=VHWUCX6osgM

Kant, I. (2012). Contestación a la pregunta: ¿Qué es la ilustración? México, D. F.: Taurus.

Martínez, N. (2014). Doctores para la industria. Sumamente, abril-mayo. Bogotá: Ediciones Semana.

McLuhan, M y Fiore, Q. (1985). Guerra y paz en la aldea global. Bogotá: Planeta-Agostini. 
Morin (2014). La finalidad del proceso educativo o la religación ética del sistema. En Consejo Nacional de Educación Superior (CESU). Propuesta de politica pública para la excelencia de la educación superior en Colombia en el escenario de la paz. Bogotá: CESU.

Nietzsche, F. (2004). El crepúsculo de los ídolos. Madrid: Alianza.

Nussbaum, M. (2001). El cultivo de la humanidad. Una defensa clásica de la reforma en la educación liberal. Barcelona: Andrés Bello.

Nussbaum, M. (2010). Sin fines de lucro. Por qué la democracia necesita de las humanidades. Barcelona: Katz Editores.

Padrón, J. (2007). Tendencias Epistemológicas de la Investigación Científica en el Siglo XXI. Cinta de Moebio, 28, 1-28.

Puzo, M. (1970). El Padrino. Barcelona: Grijalbo.

Real Academia Española (2001). Anti. En Diccionario de la lengua española (22. ${ }^{a}$ ed.). Recuperado de http://lema.rae.es/drae/?val=anti

Real Academia Española (2001). Trans. En Diccionario de la lengua española (22. ${ }^{a}$ ed.). Recuperado de http://lema.rae.es/drae/?val=trans

Rodríguez, E. (enero, 2001). La problemática actual de las humanidades. Análisis, 65-66, 15-32.

Sampedro, V. (enero-marzo, 2006). ¿Redes de nudos o vacíos? Nuevas tecnologías y tejido social. Documentación social, 140, 25-38.

Stanford Humanities Center (2014). What are the Humanities?. Stanford Humanities Center. Recuperado de: http://shc.stanford.edu/what-are-the-humanities

Universidad Santo Tomás (2004): Proyecto Educativo Institucional. Bogotá: Ediciones USTA.

Wallace, D. F. (2012). Esto es agua. Unos cuantos pensamientos, leídos para un evento importante, sobre cómo vivir la vida con compasión. Versión Kindle. Recuperado de Amazon.com

Wallerstein, I. (2001). Conocer el mundo, saber el mundo: el fin de lo aprendido: una ciencia social para el siglo XXI. Madrid: Siglo XXI.

Wolton, D. (2011). Informar no es comunicar: contra la ideología tecnológica. Barcelona: Gedisa. 